\title{
Penerapan Sistem Hazard Analisis Critical Control Point (HACCP) Pada Produk Ayam Bakar Bumbu Herb Di Divisi Katering Diet PT. Prima Citra Nutrindo Surabaya
}

\section{Implementation of Hazard Analisys Critical Control Point (HACCP) on Herb Roasted Chicken products in Division Catering Diet PT. Prima Citra Nutrindo Surabaya}

Novira Dian Rachmadia*1, Nanik Handayani ${ }^{2}$, Annis Catur Adi ${ }^{1}$

\begin{abstract}
ABSTRAK
Latar Belakang: Katering sehat sebagai tempat penyedia jasa boga diharuskan mempunyai standar keamanan yang jelas dalam menjamin mutu produknya hingga ke tangan konsumen. PT. Prima Citra Nutrindo (PCN) sebagai salah satu katering sehat telah mempunyai standar HACCP pada salah satu produknya yaitu Ayam Bakar Bumbu Herb. Pengendalian mutu makanan dengan standar HACCP perlu dilakukan mengingat kejadian foodborne illnes sangat mudah terjadi apabila keamanan pangan tidak terjamin.

Tujuan: Tujuan penelitian ini adalah untuk mengidentifikasi penerapan sistem HACCP pada produk Ayam Bakar Bumbu Herb di PT. Prima Citra Nutrindo (PCN).

Metode: Metode yang digunakan adalah metode deskriptif kualitatif meliputi observasi lapangan, diskusi, wawancara, dan tanya jawab untuk menyempurnakan penerapan HACCP pada produk Ayam Bakar Bumbu Herb.

Hasil: Tahap produksi ayam bakar bumbu Herb dimulai dari proses perebusan air hingga serving diketahui terdapat 2 tahap yang merupakan Critical Control Point yang harus diwaspadai yaitu tahap pendinginan (cooling) dan tahap penyajian (serving). Pengendalian resiko kejadian foodborne illnes pada produk Ayam Bakar Bumbu Herb dapat dilakukan dengan menjaga jeda waktu antara pendinginan dan pengemasan.

Kesimpulan: Hasil studi ini bermanfaat sebagai rekomendasi perbaikan dalam rangka mempertahankan sistem manajemen mutu yang telah tercapai serta untuk pengembangan prosedur HACCP pada produk yang lain sehingga menghasilkan produk yang aman untuk dikonsumsi.
\end{abstract}

Kata Kunci: keamanan pangan, HACCP, foodborne illness 


\begin{abstract}
Background: Healthy catering as a place of catering service providers are required to have clear safety standards in ensuring the quality of their products to the hands of consumers. PT. Prima Citra Nutrindo (PCN) as one of the healthy caterers has HACCP standard on one of its products that is Herb Roasted Chicken product. Quality control of food with HACCP standard needs to be done considering the occurrence of foodborne illnes very easily occur if food safety is not guaranteed.

Objectives: The purpose of this research is to identify the application of HACCP system on Herb Roasted Chicken product in PT. Prima Citra Nutrindo (PCN).

Methode: The method used is qualitative descriptive method including field observation, discussion, interview, and question and answer to complete the application of HACCP on Herb Roasted Chicken product.

Result: Phase production of roasted chicken Herb starts from boiling water until serving known there are 2 stages which is the Critical Control Point to watch out for the cooling and serving stages. The control of the risk of foodborne illness in Herb Roasted Chicken can be done by keeping the time lag between cooling and packaging.

Conclusions: The results of this study are useful as recommendations for improvement in order to maintain the quality management system that has been achieved and for the development of HACCP procedures on other products so as to produce products that are safe for consumption.
\end{abstract}

Keywords: food safety, HACCP, foodborne illness

\footnotetext{
*Koresponden:

dianrachmadia92@gmail.com

${ }^{1}$ Departemen Gizi Kesehatan,

Fakultas Kesehatan Masyarakat, Universitas Airlangga

2 PT. Prima Citra Nutrindo (PCN)
}

\section{PENDAHULUAN}

Industri penyelenggaraan makanan jasa boga di Indonesia dewasa ini berkembang sangat pesat. Berbagai tempat katering bermunculan menawarkan berbagai menu makanan yang beraneka ragam. Variasi menu bukan hanya menjadi daya tarik didalam makanan tersebut, tetapi kandungan gizi didalamnya menjadi indikator bagi kesehatan konsumen. Makanan yang kini mulai banyak variasi dan diminati konsumen bukan saja yang mempunyai kandungan gizi yang baik tetapi juga harus memiliki keamanan pangan yang jelas.

Pangan yang tidak aman dapat menyebabkan penyakit yang disebut dengan foodborne IIIness yaitu gejala penyakit yang timbul akibat mengkonsumsi pangan yang mengandung bahan/ senyawa beracun atau organisme patogen ${ }^{1}$. Keamanan pangan adalah kondisi dan upaya yang diperlukan untuk mencegah pangan dari kemungkinan cemaran biologis, kimia, dan benda lain yang dapat mengganggu, merugikan, dan membahayakan kesehatan manusia. Pangan yang aman dan sehat berperan penting bagi pertumbuhan dan peningkatan derajat kesehatan masyarakat ${ }^{2}$.

Salah satu cara untuk menjamin keamanan produk yaitu dengan sistem jaminan keamanan pangan yang disebut Analisis Bahaya dan Pengendalian Titik Kritis (Hazard Analysis Critical Control Point /HACCP). HACCP mempunyai peranan sangat strategis untuk menjamin keamanan produk 
pangan yang dihasilkan industri pangan sebagai acuan dalam pengelolaan keamanan pangan di dunia ${ }^{3}$.

Pada tahun 2003 dan 2004, di negaranegara Asia kasus penyakit yang disebabkan karena keracunan pangan telah meningkat karena adanya penyediaan pangan dari industri jasa boga untuk keperluan-keperluan seperti di kantin sekolah, kantin perusahaan, dan untuk keperluan sosial ${ }^{4}$. Penyebab keracunan pangan dari produk jasa boga atau katering kemungkinan dapat disebabkan adanya mikroba patogen, kondisi sanitasi dan higiene, serta tempat mengolah makanan yang buruk. Hal ini menunjukkan bahwa masih kurangnya keamanan pangan pada industri penyelenggaraan makanan.

Penelitian yang dilakukan pada 43 katering di wilayah Jakarta menunjukkan ditemukannya kuman Eschericia coli dan Staphylococcus aureus pada sample makanan, yang menunjukkan perlu pengecekan kebersihan dan sanitasi pada usaha katering ${ }^{5}$. Semua jenis produk pangan mempunyai resiko menjadi bahaya jika penanganan produknya tidak dilakukan dengan baik. Diperlukan pengawasan dan pemantauan ekstra dimulai dari penerimaan bahan baku hingga produk aman sampai ke tangan konsumen.

Tujuan penelitian ini adalah untuk mengidentifikasi penerapan sistem HACCP pada produk Ayam Bakar Bumbu Herb di PT. Prima Citra Nutrindo (PCN). Hasil studi ini bermanfaat sebagai rekomendasi perbaikan dalam rangka mempertahankan sistem manajemen mutu yang telah tercapai serta untuk pengembangan prosedur HACCP pada produk yang lain sehingga menghasilkan produk yang aman untuk dikonsumsi. Hal ini sesuai dengan peraturan yang secara tegas telah diatur bahwa produsen produk pangan harus mampu untuk memenuhi berbagai persyaratan produksi sehingga dapat memberikan jaminan dihasilkannya produk pangan yang aman dan bermutu bagi konsumen ${ }^{6}$.

\section{METODE}

Metode yang digunakan pada kegiatan ini meliputi : Identifikasi Kebijakan Mutu Dan Penerapan Sistem HACCP di PT PCN
Identifikasi dilakukan untuk mendapatkan gambaran mengenai proses produksi.

Identifikasi penerapan sistem HACCP dilakukan dengan menelusuri prinsip-prinsip dasar penerapan HACCP pada produk Ayam Bakar Bumbu Herb. Sistem HACCP terdiri dari 12 tahap yang termasuk didalamnya 7 prinsip HACCP. Lima tahap awal terdiri dari penyusunan tim HACCP, deskripsi produk, identifikasi penggunaan produk, menyusun diagram alir, dan verifikasi diagram alir.

Penyusunan Tujuh Prinsip Rencana HACCP Ketujuh prinsip itu terdiri dari analisa bahaya, penentuan titik kritis (CCP), penetapan batas kritis untuk setiap CCP (Critical Limit), menetapkan sistem pemantuan untuk sistem HACCP, dan penetapan tindakan koreksi untuk setiap CCP.

Observasi Lapangan Observasi dilakukan untuk mengamati kondisi lingkungan kerja dan proses produksi di Catering Diet yang meliputi proses penerimaan bahan baku, persiapan, pengolahan, penyajian, sampai proses distribusi dan pemasaran. Dimana dari hasil observasi ini akan dibandingkan dengan referensi teori yang relevan dengan permasalahan yang ditemukan.

Diskusi dan Wawancara Mengenai Proses Penerapan Sistem HACCP Wawancara dilakukan untuk menggali informasi terkait dengan sistem HACCP Ayam Bakar Bumbu Herb dan penerapan HACCP dalam proses produksinya. Diskusi dan tanya jawab dilakukan kepada Direktur Perusahaan, Pekerja Office, dan Pekerja Lapangan. Berdasarkan hal tersebut, peneliti dapat mengajukan saran dan rekomendasi mengenai saran perbaikan dan penerapan HACCP dalam rangka mempertahankan sistem manajemen mutu yang telah tercapai.

\section{HASIL DAN PEMBAHASAN}

PT. Prima Citra Nutrindo ( PT. PCN) merupakan salah satu perusahaan bidang jasa boga untuk memenuhi kebutuhan konsumen dengan menerapkan konsep personalize. Konsep ini merupakan pelayanan dengan menyesuaikan kebutuhan individu berdasarkan antropometri, usia, status gizi, 
riwayat penyakit yang dilengkapi dengan hasil penunjang medis atau target kesehatan yang dinginkan oleh konsumen.

Jasa boga atau katering adalah perusahaan atau perorangan yang melakukan kegiatan pengolahan bahan makanan yang dapat disajikan di luar tempat usaha atau berdasarkan pesanan konsumen dan merupakan makanan yang siap saji ${ }^{7}$. Industri jasaboga terdiri dari berbagai macam golongan dan PT PCN termasuk dalam jasa boga golongan $\mathrm{B}$ yang melayani kebutuhan khusus seperti katering untuk rumah sakit, asrama, perusahaan, dan pelayanan kesehatan. PT. PCN menerapkan sistem ISO 22000 dimana didalamnya terdapat sistem Produksi GMP (Good Manufacturing Practice) dan standar HACCP sehingga kualitas bahan makanan dan proses bahan makanan termonitoring dengan baik sesuai dengan ketentuan yang ada.

PT. PCN memiliki beberapa brand salah satunya adalah Catering Diet. Produk yang dihasilkan dari divisi Catering Diet adalah masakan main course yang setiap menunya melibatkan proses perlakuan yang berbeda beda. Salah satu menunya adalah Ayam Bakar Bumbu Herb. Ayam Bakar Bumbu Herb merupakan ayam bakar yang memiliki ciri khas, terutama pada bumbu rempahnya yaitu oregano, thyme leaves, dan bay leaves.

Penerapan HACCP pada proses pembuatan Kepiting Saos Tambora di RM Kepiting Tambora dapat memberikan pengawasan keamanan makanan mulai dari penggunaan diagram alir untuk menggambarkan proses pembuatan Kepiting Saos Tambora, sehingga dapat mengidentifikasi bahaya -bahaya potensial keamanan produk makanan ${ }^{8}$. Dilanjutkan dengan menentukan kriteria batas kritis untuk setiap titik kendali kritis (CCP) untuk memberikan usulan tindakan perbaikan dan menetapkan anggota tim yang harus bertanggung jawab. Sistem HACCP pada perusahaan harus menjabarkan secara rinci tindakan - tindakan perbaikan jika bahaya keamanan pangan terjadi pada produk, sehingga menurunkan presentase terjadinya produk cacat yang terlanjur sampai ke pihak konsumen.

Tahap Penerapan Hazard Analysis Critical
Control Points (HACCP) di PT Prima Citra
Nutrindo (PCN)
Pengamatan dilakukan pada pelaksanaan pemenuhan standar keamanan pangan dengan HACCP produk sampel Ayam Bakar Bumbu Herb. Untuk melakukan HACCP diperlukan 12 langkah dengan penerapan 7 prinsip HACCP. Langkah awal dalam penerapan HACCP adalah pembentukan Tim HACCP pada sistem produksi Ayam Bakar Bumbu Herb divisi Catering Diet, dengan hasil analisa sebagai berikut:

\section{Pembentukan Tim HACCP}

Tim HACCP yang terdapat pada PT Prima Citra Nutrindo terdiri dari beberapa anggota dengan disiplin ilmu yang berbedabeda. Anggota Tim berjumlah 4 orang dan masing-masing mempunyai tugas mulai dari penanggung jawab dapur pasien, mutu resiko, rumah tangga, dan teknik. Pemantauan dilakukan setiap 6 bulan sekali dan dikoreksi oleh penanggung jawab dapur yang menjadi salah satu anggota tim HACCP.

\section{Layout Dapur Catering Diet}

Denah dapur divisi Catering Diet PT PCN dibagi menjadi 2 ruangan yaitu area prepare dan area produksi. Area prepare adalah tempat persiapan bahan-bahan untuk menu masakan katering keesokan harinya. Area produksi merupakan tempat eksekusi proses pemasakan bahan-bahan yang telah dipersiapkan sebelumnya di area prepare. 


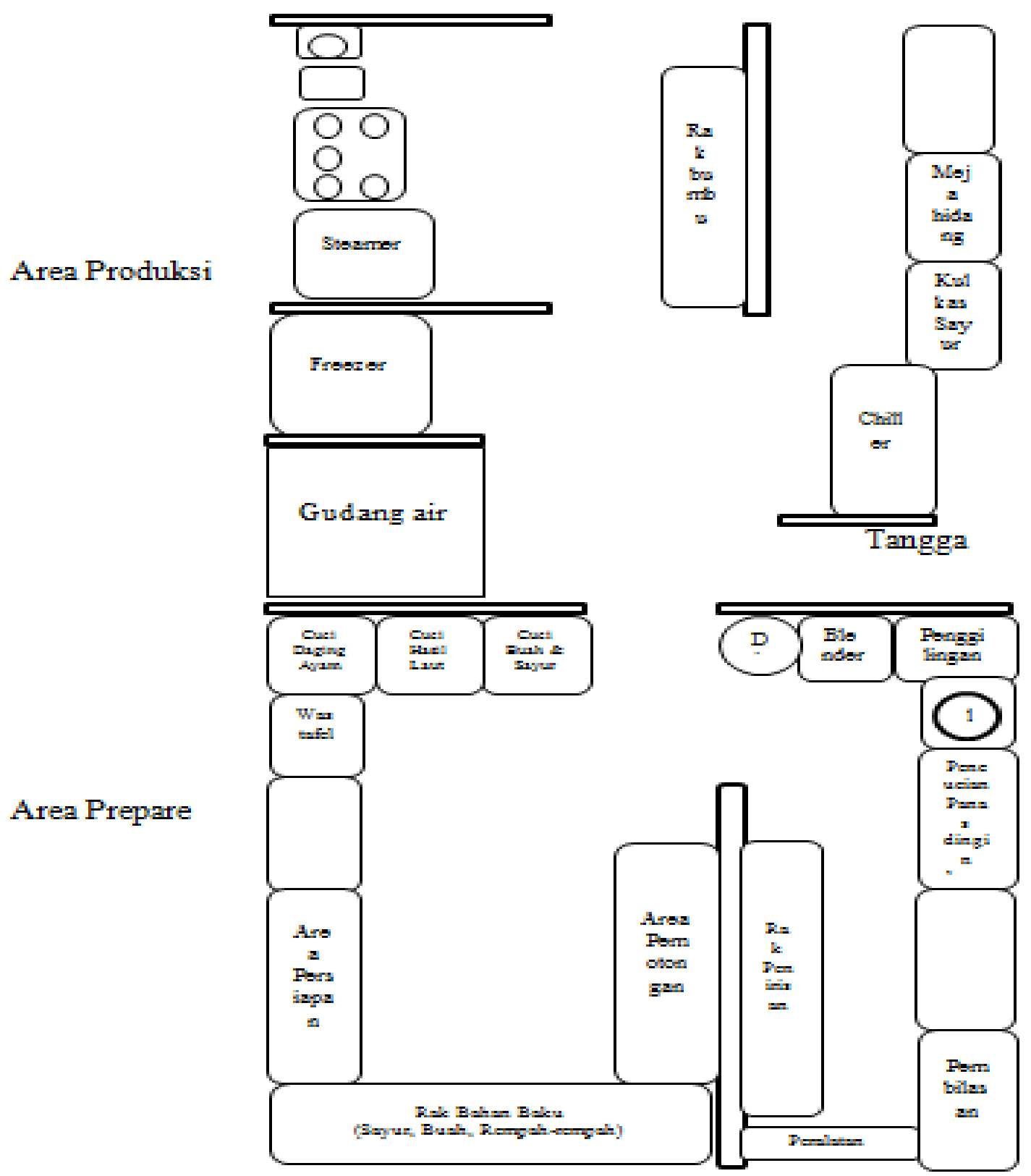

\section{Gambar 1. Layout Dapur Catering diet}

\section{Deskripsi Produk}

Ayam bakar merupakan masakan olahan dari daging ayam yang diberi bumbu kecap hingga madu dan didiamkan dalam waktu tertentu untuk menghasilkan rasa manis dan gurih. Sebelum dipanggang daging ayam direbus dengan jahe dan jeruk nipis untuk menghilangkan rasa amis, kemudian daging direndam dengan bumbu bakar selama beberapa menit untuk selanjutnya melalui proses pemanggangan. Yang membuat produk ayam bakar ini berbeda dari yang lain adalah dari campuran bumbu rempah didalamnya yaitu oregano, thyme leaves, dan bay leaves. Bahan ini dicampurkan pada ayam yang telah direbus terlebih dahulu, kemudian dipanggang dalam oven. Deskripsi produk dan pengolahan Ayam Bakar Bumbu Herb secara lengkap dapat dilihat sebagai berikut: 
Nama Produk

Bahan Baku

Metoda Pengolahan

Jenis Kemasan

Kondisi Penyimpanan

Masa Simpan

Cara Penyajian

Metoda Distribusi

Identifikasi penggunaan
: Ayam Bakar Bumbu Herb

: 1. Daging Ayam

2. Bawang Putih

3. Jahe

4. Daun Jeruk

5. Ketumbar

6. Bumbu

7. Rempah-rempah (Oregano, thyme leaves, bay leaves)

8. Saos Tomat

9. Kecap Manis

: 1. Perebusan pada suhu $100^{\circ} \mathrm{C}$, selama 10 menit

2. Pemanggangan pada suhu $200^{\circ} \mathrm{C}$ selama 30 menit

: Conver Pack

: Disimpan dalam ruang yang sejuk dan kering.

: 4 jam

: Ready to eat

: Angkut dengan kurir dengan tempat yang bersih, suhu ruang \& bebas dari bau.

: Konsumsi Umum

Tabel 1. Deskripsi Bahan

\begin{tabular}{|c|c|}
\hline Jenis Bahan Baku & Kriteria penerimaan Bahan Baku \\
\hline Ayam & $\begin{array}{l}\text { Karakteristik fisik: } \\
\text { 1. Diterima dalam keadaan segar dan langsung digunakan untuk bahan } \\
\text { baku proses atau disimpan sebagai stock dalam keadaan dibekukan. } \\
\text { 2. Diterima hanya dari pemasok yang telah disetujui oleh Tim HACCP } \\
\text { (dengan memeriksa nota pembelian atau pengiriman dari pemasok) }\end{array}$ \\
\hline Bawang Putih & $\begin{array}{l}\text { Karakteristik fisik: } \\
\text { - } \quad \text { Dalam bentuk kupas, tersimpan dalam plastik. }\end{array}$ \\
\hline Jahe & $\begin{array}{l}\text { Karakteristik fisik: } \\
\text { - Dalam bentuk utuh, tidak ada tanda busuk, sudah dicuci bersih, dan } \\
\text { tersimpan dalam kemasan plastik. }\end{array}$ \\
\hline Daun Jeruk & $\begin{array}{l}\text { Karakteristik fisik: } \\
\text { Dalam bentuk utuh dan tersimpan dalam kemasan, }\end{array}$ \\
\hline Ketumbar & $\begin{array}{l}\text { Karakteristik fisik: } \\
\text { - } \quad \text { Dalam bentuk kering, tersimpan dalam kemasan yang tidak bocor }\end{array}$ \\
\hline $\begin{array}{l}\text { Bumbu (garam, gula } \\
\text { pasir, MSG, BP) }\end{array}$ & $\begin{array}{l}\text { Karakteristik fisik: } \\
\text { - } \quad \text { Dalam bentuk campuran kering, tersimpan dalam kemasan yang tidak bocor }\end{array}$ \\
\hline $\begin{array}{l}\text { Rempah-rempah } \\
\text { (Oregano, thyme } \\
\text { leaves, bay leaves) }\end{array}$ & $\begin{array}{l}\text { Karakteristik fisik: } \\
\text { - Diterima dalam botol kemasan, tersimpan dalam kemasan yang tertutup dan } \\
\text { bersegel }\end{array}$ \\
\hline Kecap Manis & $\begin{array}{l}\text { Karakteristik fisik: } \\
\text { - Diterima dalam botol kemasan, tersimpan dalam kemasan yang tertutup dan } \\
\text { bersegel }\end{array}$ \\
\hline Saos Tomat & $\begin{array}{l}\text { Karakteristik fisik: } \\
\text { - Diterima dalam botol kemasan, tersimpan dalam kemasan yang tertutup dan } \\
\text { bersegel }\end{array}$ \\
\hline
\end{tabular}




\section{Deskripsi Bahan Baku}

Bahan-bahan yang dibutuhkan dalam pengolahan produk Ayam Bakar Bumbu Herb menggunakan bahan baku basah dan kering. Bahan Baku basah yaitu Ayam, bawang putih, jahe, dan daun jeruk. Sedangkan bahan baku kering antara lain seperti ketumbar, bumbu (garam, gula pasir, MSG, BP), rempah-rempah (oregano, thyme leaves, bay leaves), serta kecap manis dan saos tomat. Deskripsi Bahan Baku dapat dilihat pada Tabel 1.

Konsumsi produk Ayam Bakar bumbu Herb diberikan kepada pasien rumah sakit yang didistribusikan awal kepada bagian instalasi gizi atau dapur rumah sakit kemudian didistribusikan kepada pasien.Ayam Bakar yang telah diberikan dapat langsung dikonsumsi atau disimpan terlebih dahulu, akan tetapi tidak dapat melewati waktu simpan yang telah ditentukan. Batas umur simpan yang ditetapkan oleh pihak PT PCN yaitu 4 jam setelah penyajian dari dapur dengan pertimbangan berdasarkan uji laboratorium masakan yang melewati batas 4 jam mempunyai resiko berkembangnya bakteri pada masakan. Konsumsi produk Ayam Bakar bumbu Herb diberikan kepada pasien rumah sakit yang didistribusikan awal kepada bagian instalasi gizi atau dapur rumah sakit kemudian didistribusikan kepada pasien. Ayam Bakar yang telah diberikan dapat langsung dikonsumsi atau disimpan terlebih dahulu, akan tetapi tidak dapat melewati waktu simpan yang telah ditentukan. Batas umur simpan yang ditetapkan oleh pihak PT PCN yaitu 4 jam setelah penyajian dari dapur dengan pertimbangan berdasarkan uji laboratorium masakan yang melewati batas 4 jam mempunyai resiko berkembangnya bakteri pada masakan.

\section{Penyusunan Diagram Alir}

Diagram alir yang dibuat berdasarkan pengamatan pada proses produksi Ayam Bakar Bumbu Herb dimulai dari bahan diterima hingga menjadi masakan yang telah siap disajikan kepada konsumen. Diagram dibuat dan langsung diverifikasi pada kondisi proses sebenarnya di lapangan. Diagram alir dapat dilihat pada gambar 2. Konfirmasi Bagan Alir di Lapangan

Konfirmasi bagan alir merupakan pemeriksaan ulang antara diagram alir yang sudah dibuat oleh peneliti dengan proses produksi yang terjadi sesungguhnya di PT Prima Citra Nutrindo. Berdasarkan bagan alir yang telah dibuat peneliti untuk HACCP produk Ayam Bakar Bumbu Herb sudah sesuai dengan document control HACCP di PT Prima Citra Nutrindo.

Identifikasi Bahaya (Prinsip 1)

Tahap identifikasi bahaya merupakan tahapan untuk memberi gambaran mengenai potensi bahaya yang mungkin dapat terjadi dari keseluruhan proses produksi. Pemeriksaan ini harus dilaksanakan sebagai tahap utama untuk mengidentifikasi semua bahaya yang terjadi bila produk pangan dikonsumsi. Jenis bahaya yang mungkin terdapat di dalam makanan dibedakan atas 3 kelompok yaitu: Bahaya fisik berupa bendabenda asing yang seharusnya tidak boleh terdapat di dalam makanan, Bahaya biologis disebabkan oleh bakteri patogen, virus atau parasit yang dapat menyebabkan keracunan ataupun penyakit infeksi, Bahaya kimia karena tertelannya toksin alami atau bahan kimia yang beracun. Potensi bahaya berdasarkan pengamatan selama proses produksi dapat dilihat pada Tabel 2. 


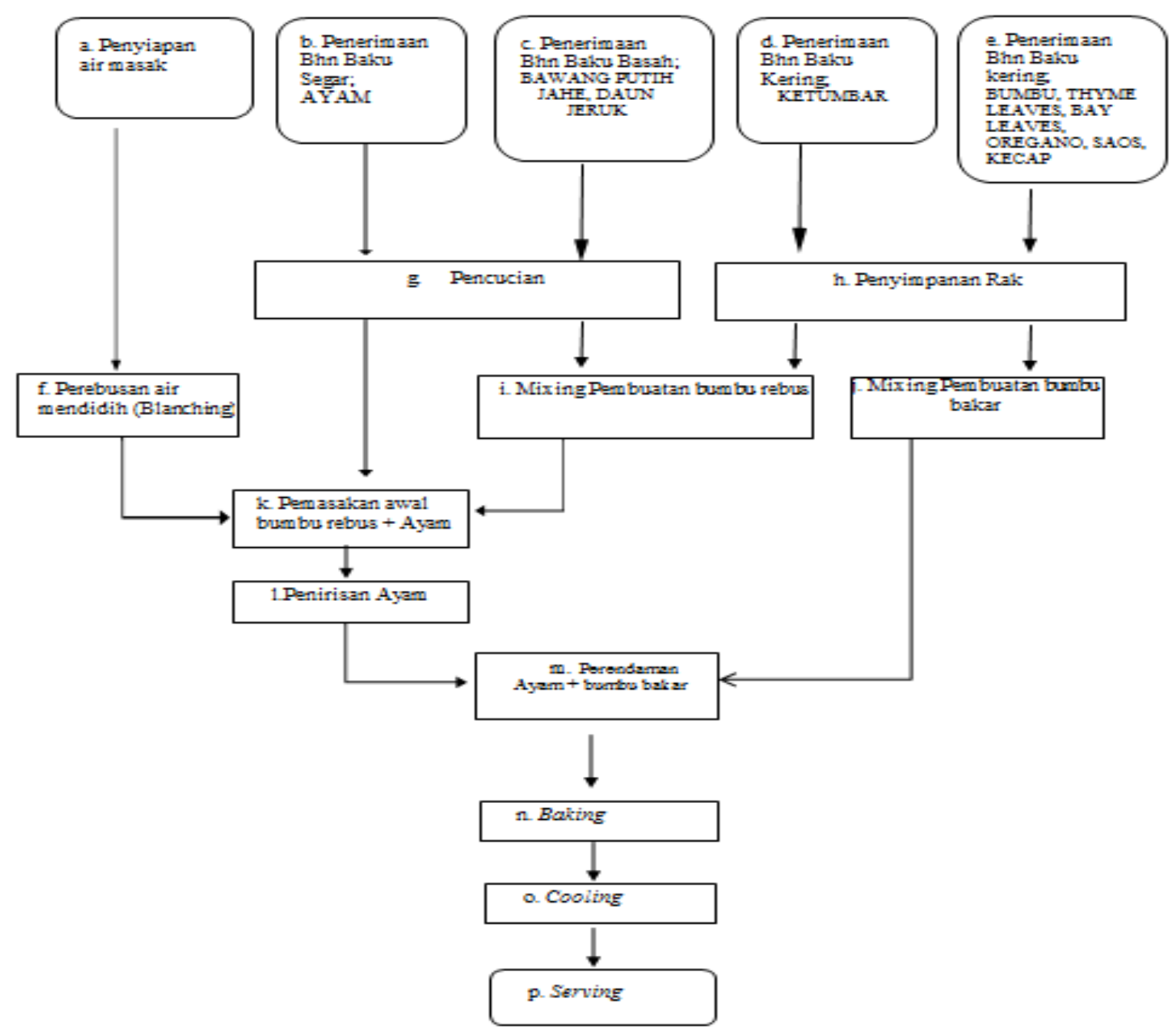

Gambar 2. Diagram Alir

Tabel 2. Identifikasi bahaya pada proses pembuatan produk

\begin{tabular}{|c|c|c|c|}
\hline \multirow{2}{*}{ LANGKAH } & \multicolumn{2}{|c|}{ POTENSI BAHAYA } & \multirow{2}{*}{ SUMBER BAHAYA } \\
\hline & F/B/K & JENIS & \\
\hline \multirow{3}{*}{$\begin{array}{l}\text { Penyiapan Air } \\
\text { Perebusan }\end{array}$} & $\mathrm{F}$ & Tidak ada & - \\
\hline & $\mathrm{B}$ & E. Coli & Kontaminasi dari air \\
\hline & K & Tidak Ada & - \\
\hline \multirow{2}{*}{$\begin{array}{l}\text { Penerimaan Bahan Baku } \\
\text { Segar; AYAM }\end{array}$} & $\mathrm{F}$ & Debu, kerikil & Penanganan Bongkar Muat \\
\hline & B & Staphylococcusaureus & $\begin{array}{l}\text { Kontaminasi tangan pekerja, } \\
\text { mengandung bakteri }\end{array}$ \\
\hline \multirow[t]{2}{*}{$\begin{array}{l}\text { Penerimaan Bahan Baku } \\
\text { Basah; BAWANG PUTIH }\end{array}$} & $\mathrm{F}$ & $\begin{array}{l}\text { Debu, Kerikil, } \\
\text { Serangga }\end{array}$ & $\begin{array}{l}\text { Penanganan pengemasan dari } \\
\text { pemasok }\end{array}$ \\
\hline & B & Tidak Ada & - \\
\hline $\begin{array}{l}\text { Penerimaan Bahan Baku } \\
\text { Basah; JAHE }\end{array}$ & $\mathrm{F}$ & Debu, Kerikil & $\begin{array}{l}\text { Penanganan pengemasan dari } \\
\text { pemasok }\end{array}$ \\
\hline $\begin{array}{l}\text { Penerimaan Bahan Baku } \\
\text { Basah; DAUN JERUK }\end{array}$ & $\mathrm{F}$ & Debu, Kerikil & $\begin{array}{l}\text { Penanganan saat pengemasan } \\
\text { dari pemasok }\end{array}$ \\
\hline
\end{tabular}




\begin{tabular}{|c|c|c|c|}
\hline \multirow{2}{*}{$\begin{array}{l}\text { Penerimaan Bahan Baku } \\
\text { Kering; KETUMBAR }\end{array}$} & \multirow{2}{*}{$\begin{array}{l}\mathrm{F} \\
\mathrm{B}\end{array}$} & Debu, Kerikil & \multirow{2}{*}{$\begin{array}{l}\text { Penanganan Bongkar Muat } \\
\text { Kebocoran Kemasan }\end{array}$} \\
\hline & & Tidak Ada & \\
\hline \multirow{2}{*}{$\begin{array}{l}\text { Penerimaan Bahan } \\
\text { Baku Kering;BUMBU }\end{array}$} & $\mathrm{F}$ & Debu, Kerikil & \multirow{2}{*}{$\begin{array}{l}\text { Penanganan Bongkar Muat } \\
\text { - }\end{array}$} \\
\hline & $\mathrm{B}$ & Tidak Ada & \\
\hline \multirow{2}{*}{$\begin{array}{l}\text { Penerimaan Bahan Baku } \\
\text { Kering;THYME LEAVES }\end{array}$} & $\mathrm{F}$ & Tidak Ada & \multirow[b]{2}{*}{-} \\
\hline & B & Tidak Ada & \\
\hline \multirow{2}{*}{$\begin{array}{l}\text { Penerimaan Bahan Baku } \\
\text { Kering;OREGANO }\end{array}$} & $\mathrm{F}$ & Tidak Ada & \multirow{2}{*}{-} \\
\hline & $\mathrm{B}$ & Tidak Ada & \\
\hline \multirow{2}{*}{$\begin{array}{l}\text { Penerimaan Bahan Baku } \\
\text { Kering;BAY LEAVES }\end{array}$} & $\mathrm{F}$ & Tidak Ada & \multirow{2}{*}{-} \\
\hline & $\mathrm{B}$ & Tidak Ada & \\
\hline \multirow{2}{*}{$\begin{array}{l}\text { Penerimaan Bahan Baku } \\
\text { Kering;SAOS TOMAT }\end{array}$} & $\mathrm{F}$ & Tidak Ada & \multirow[b]{2}{*}{-} \\
\hline & $\mathrm{B}$ & Tidak Ada & \\
\hline \multirow{2}{*}{$\begin{array}{l}\text { Penerimaan Bahan Baku } \\
\text { Kering;KECAP MANIS }\end{array}$} & $\mathrm{F}$ & Tidak Ada & \multirow{2}{*}{-} \\
\hline & $\mathrm{B}$ & Tidak Ada & \\
\hline $\begin{array}{l}\text { Perebusan Air Mendidih } \\
\text { (Blanching) }\end{array}$ & $\mathrm{B}$ & Tidak Ada & - \\
\hline Pencucian & $\mathrm{F}$ & $\begin{array}{l}\text { Sisa kotoran, lemak } \\
\text { atau minyak }\end{array}$ & Kebersihan Alat yang kurang baik \\
\hline Penyimpanan Rak & $\mathrm{F}$ & Debu, Kerikil & $\begin{array}{l}\text { Kebersihan tempat yg kurang } \\
\text { baik }\end{array}$ \\
\hline $\begin{array}{l}\text { Mixing Pembuatan } \\
\text { Bumbu Rebus }\end{array}$ & $\mathrm{K}$ & $\begin{array}{l}\text { Logam, cemaran } \\
\text { timbal }\end{array}$ & $\begin{array}{l}\text { Kontaminasi logam dari blender } \\
\text { yang digunakan }\end{array}$ \\
\hline $\begin{array}{l}\text { Mixing Pembuatan } \\
\text { Bumbu Bakar }\end{array}$ & $\mathrm{K}$ & Logam & $\begin{array}{l}\text { Kontaminasi logam dari blender } \\
\text { yang digunakan }\end{array}$ \\
\hline $\begin{array}{l}\text { Pemasakan awal bumbu } \\
\text { rebus + daging ayam }\end{array}$ & $\mathrm{B}$ & Tidak ada & - \\
\hline Penirisan daging ayam & $\mathrm{B}$ & Salmonella & $\begin{array}{l}\text { Kontaminasi dari Alat \& Personel } \\
\text { yang tidak bersih }\end{array}$ \\
\hline $\begin{array}{l}\text { Perendaman daging ayam } \\
+ \text { bumbu bakar }\end{array}$ & $\mathrm{B}$ & Salmonella & $\begin{array}{l}\text { Kontaminasi dari lingkungan } \\
\text { karena di tempat terbuka }\end{array}$ \\
\hline Baking & $\mathrm{K}$ & Tidak ada & - \\
\hline \multirow[t]{2}{*}{ Cooling } & $\mathrm{F}$ & $\begin{array}{l}\text { Debu, Kerikil, } \\
\text { Serangga }\end{array}$ & $\begin{array}{l}\text { Lingkungan sekitar tempat } \\
\text { pendinginan yang tidak tertutup }\end{array}$ \\
\hline & $\mathrm{B}$ & Salmonella & $\begin{array}{l}\text { Kontaminasi saat daging telah } \\
\text { dingin }\end{array}$ \\
\hline Serving & $\mathrm{F}$ & $\begin{array}{l}\text { Debu, kotoran lain, } \\
\text { rambut }\end{array}$ & $\begin{array}{l}\text { Lingkungan sekitar, tidak ditutup } \\
\text { dengan penutup makanan }\end{array}$ \\
\hline
\end{tabular}

Keterangan: $\mathrm{F}=$ Fisik, $\mathrm{B}=$ Biologi, $\mathrm{K}=$ Kimia

Penentuan Critical Control Point (CCP) (Prinsip 2)

Identifikasi penentuan titik kendali kritis atau critical control point pada produksi Ayam Bakar Bumbu Herb Divisi Catering Diet dilakukan mulai dari proses persiapan air perebusan hingga penyajian. CCP ditetapkan berdasarkan analisa bahaya yang telah ditetapkan. Penetapan CCP biasa diterapkan dengan decision treeatau biasa disebut 
dengan pohon keputusan. Pohon keputusan diterapkan pada sumber bahan baku dan pendukung, tahapan proses, serta formulasi sesuai dengan bahayanya masingmasing.

Berdasarkan hasil pengamatan yang sudah dilakukan pada proses pembuatan Ayam Bakar Bumbu Herb, didapatkan dua proses yang memiliki CCP yaitu proses cooling (pendinginan) dan serving (penyajian). Hal ini dapat dijelaskan sebagai berikut :

\section{Proses Cooling (Pendinginan)}

Pada proses ini tempat untuk mendinginkan produk berada di tempat yang terbuka dan tidak tertutup dengan baik di ruang pengolahan. Menurut Peraturan Menteri Kesehatan Republik Indonesia Tentang Higiene Sanitasi Jasaboga, mengenai persyaratan yang sudah ditetapkan untuk jasa boga katering golongan B bahwa pada ruang pengolahan makanan harus terpisah dari ruang tempat penyimpanan bahan makanan ${ }^{9}$. Apabila hal ini diabaikan akan memunculkan kontaminasi dari lingkungan yang terjadi baik fisik maupun biologi. Pada proses ini perlu dilakukan penempatan pendinginan produk di tempat yang lebih steril dengan sirkulasi yang baik sehingga meminimalkan resiko kontaminan yang terjadi.

\section{Proses Serving (Penyajian)}

Pada proses penyajian terbukanya makanan yang disajikan menjadi faktor yang beresiko terjadi kontaminasi. Ruang Penyajian yang menjadi satu dengan bagian packaging butuh perhatian lebih terkait higiene sanitasi karyawannya. Karena setidaknya sebelum dilakukan packaging sebaiknya produk tetap ditutup terlebih dahulu selama proses selanjutnya akan dilakukan. Meskipun sudah menggunakan APD tetapi banyaknya jumlah karyawan yang berada di ruang packaging dapat meningkatkan resiko kontaminasi silang antara bahan makanan dan lingkungan sekitar.

Proses yang merupakan CCP harus dilakukan dengan benar sesuai SOP, agar menghilangkan bahaya yang terjadi. Kelalaian pada saat melakukan beberapa proses dapat menimbulkan bahaya pada sistem produksi. Proses yang merupakan $\mathrm{CP}$ juga tetap memerlukan kontrol untuk pencegahan potensi bahaya.

\section{Penentuan Batas Kritis Di Setiap Critical Control Points (CCP) (Prinsip 3)}

Berdasarkan identifikasi bahaya dan titik kendali kritis pada produksi Ayam Bakar bumbu Herb, maka batas kritis untuk mencegah bahaya biologis, fisik dan kimiawi pada proses pengolahan pangan dapat dilihat pada Tabel 3. Produksi ayam bakar masih terdapat beberapa proses pengerjaan yang dapat menimbulkan terjadinya risiko terhadap olahan pangan. Risiko yang dapat terjadi antara lain, yaitu tercemarnya olahan pangan dikarenakan kondisi ruangan cooling yang kurang mendukung, kebersihan lingkungan pada ruang serving dan packaging serta APD karyawan.

Dalam pelaksanaannya PT PCN yang telah memegang sertifikat ISO 22000 mampu melaksanakan sistem HACCP dengan baik. Proses pengecekkan yang dilakukan tiap 6 bulan sekali sesuai dengan syarat minimal pelaksanaan HACCP pada ISO 22000. Tahap Produk ayam bakar bumbu Herb dimulai dari proses perebusan air hingga serving diketahui terdapat 2 tahap yang merupakan Critical Control Point yang harus diwaspadai yaitu tahap pendinginan (cooling) dan penyajian (serving). Document control HACCP pihak PT PCN sendiri memiliki titik kritis yang sama yakni pada proses cooling dan serving. Titik kritis ini berdasarkan tingkat yang paling riskan terjadinya kontaminasi silang. Pada ruangan yang digunakan untuk tahap cooling sendiri mempunyai suhu yang tinggi, disamping untuk proses pengolahan juga dikarenakan kurang cukupnya Air conditioner AC yang dipasang.

Tahap cooling yang digunakan untuk pendinginan berada di ruang yang terbuka dan rawan kontaminan. Proses pendinginan sendiri membutuhkan waktu dimana terdapat jeda tunggu yang memicu berkembang biaknya bakteri. Jeda waktu antara pendinginan dan penyajian dianggap kritis karena dapat menyebabkan kontaminasi silang dari udara. 
Tabel 3. Batas Kritis CCP Produk Ayam Bakar Bumbu Herb

\begin{tabular}{|c|c|c|c|c|c|}
\hline \multirow[t]{2}{*}{ CCP } & \multirow[t]{2}{*}{$\begin{array}{l}\text { Jenis } \\
\text { Bahaya }\end{array}$} & \multirow[t]{2}{*}{$\begin{array}{l}\text { Prinsip } 3 \\
\text { Batas Kritis }\end{array}$} & $\begin{array}{l}\text { Prinsip } 4 \\
\text { Pemantauan }\end{array}$ & \multirow{2}{*}{$\begin{array}{l}\text { Prinsip } 5 \\
\text { Koreksi dan } \\
\text { Tindakan Koreksi }\end{array}$} & \multirow[t]{2}{*}{$\begin{array}{l}\text { Prinsip } 6 \\
\text { Verifikasi }\end{array}$} \\
\hline & & & $\begin{array}{l}\text { What-where- } \\
\text { when-who- } \\
\text { how }\end{array}$ & & \\
\hline Cooling & $\begin{array}{l}\text { Terdapat } \\
\text { debu atau } \\
\text { serangga, } \\
\text { resiko } \\
\text { kontaminan } \\
\text { patogen } \\
\text { udara } \\
\end{array}$ & $\begin{array}{l}\text { Penggunaan } \\
\text { penutup } \\
\text { tudung saji } \\
\text { atau pelindung }\end{array}$ & $\begin{array}{l}\text { Kondisi } \\
\text { ruangan, } \\
\text { kondisi wadah } \\
\text { untuk tempat } \\
\text { ayam yang di } \\
\text { dinginkan. }\end{array}$ & $\begin{array}{l}\text { Tempat pendinginan } \\
\text { yang memiliki } \\
\text { sirkulasi yang baik } \\
\text { dan tertutup agar } \\
\text { terhindar } \\
\text { kontaminasi fisik } \\
\text { dan biologi }\end{array}$ & $\begin{array}{l}\text { Memberikan } \\
\text { teguran } \\
\text { kepada chef } \\
\text { saat wadah } \\
\text { tidak tertutup }\end{array}$ \\
\hline Serving & $\begin{array}{l}\text { Terdapat } \\
\text { debu dan } \\
\text { bakteri di } \\
\text { sekitar yang } \\
\text { bersumber } \\
\text { dari } \\
\text { masakan } \\
\text { yang tidak } \\
\text { tertutup } \\
\text { dan } \\
\text { karyawan } \\
\text { yang } \\
\text { melakukan } \\
\text { pacgkaging }\end{array}$ & $\begin{array}{l}\text { Penutup } \\
\text { masakan dan } \\
\text { sirkulasi udara } \\
\text { tempat serving } \\
\text { dan packaging }\end{array}$ & $\begin{array}{l}\text { Kebersihan } \\
\text { lingkungan } \\
\text { pada ruang } \\
\text { serving dan } \\
\text { packaging serta } \\
\text { APD karyawan }\end{array}$ & $\begin{array}{l}\text { Karyawan yang ikut } \\
\text { serta dalam proses } \\
\text { packaging menjaga } \\
\text { kebersihan diri dan } \\
\text { dikurangi jumlahnya } \\
\text { agar sirkulasi udara } \\
\text { lancar. }\end{array}$ & $\begin{array}{l}\text { Menutup } \\
\text { masakan yang } \\
\text { disajikan, } \\
\text { menjaga } \\
\text { sirkulasi } \\
\text { ruangan tetap } \\
\text { terjaga } \\
\text { dengan tidak } \\
\text { membuka } \\
\text { dan tutp } \\
\text { ruangan } \\
\text { pemorsian }\end{array}$ \\
\hline
\end{tabular}

Hal ini dapat diantisipasi dengan proses cooling Ayam Bakar Bumbu Herb diletakan di tray yang tertutup plastik pelindung atau cover untuk tray agar tidak terkontaminasi oleh debu ataupun bakteri. Ruangan juga berada di ruang pengolahan yang mempunyai suhu tinggi diperlukan penambahan Air conditioner (AC) untuk sirkulasi udara yang lebih terjaga.

Pada tahap serving menggunakan ruangan yang menjadi satu tempat dengan packaging dan pemorsian sehingga diwajibkan bagi karyawan yang memasuki ruangan tersebut untuk selalu menggunakan APD. APD minimal penutup kepala dan masker berfungsi untuk mencegah terjadinya kontaminasi antara mikroorganisme dari mulut pekerja dengan makanan yang diolah ${ }^{10}$.

Penanggung jawab divisi Catering Diet mencatat kepatuhan penjamah makanan alam hal kepatuhan menggunakan alat yang wajib digunakan yaitu APD saat kontak langsung dengan makanan agar dapat lebih meningkatkan kesadaran setiap pekerja dan mengurangi terjadinya kontaminasi terhadap makanan. Kelebihan dari area ini adalah tersedianya exhaust fan. Peletakkan exhaust fan tepat diatas rak meja pada sudut kanan ruang pemorsian. Exhaust fan berfungsi untuk menghisap udara dalam ruang untuk dibuang ke luar, dan pada saat yang bersamaan juga akan menarik udara segar dari luar ke dalam ruangan. Penggunaan exhaust fan juga bertujuan untuk mengendalikan debu beracun/ asap/gas dan uap dan jika tidak dikendalikan akan memberikan dampak kesehatan bagi pekerja.

\section{KESIMPULAN}

Selama tahap proses pembuatan Ayam Bakar Bumbu Herb Divisi Catering Diet 
yang dimulai dari persiapan air perebusan hingga penyajian terdapat 3 jenis potensi bahaya yang ditinjau dari segi biologis, fisik, dan kimia. Dalam pelaksanaannya PT PCN yang telah memegang sertifikat ISO 22000 mampu melaksanakan sistem HACCP dengan baik. Tahap Produk ayam bakar bumbu Herb dimulai dari proses perebusan air hingga serving diketahui terdapat 2 tahap yang merupakan Critical Control Point yang harus diwaspadai yaitu tahap pendinginan (cooling) dan penyajian (serving). Titik kritis pada tahap pendinginan (cooling) dan penyajian (serving) merupakan titik-titik yang dianggap paling memungkinkan terjadinya kontaminasi. Jeda waktu antara pendinginan dan pengemasan dianggap kritis karena dapat menyebabkan kontaminasi silang dari udara.

\section{ACKNOWLEDMENT}

Puji syukur kami panjatkan kepada Allah SWT atas segala rahmat dan karuniaNya sehingga dapat terselesaikannya artikel Jurnal yang berjudul Penerapan Sistem Hazard Analisis Critical Control Point (HACCP) Pada Produk Ayam Bakar Bumbu Herb Di Divisi Katering Diet PT. Prima Citra Nutrindo Surabaya. Peneliti ingin menyampaikan ucapan terimakasih kepada Ibu Lailatul Muniroh, S.KM., M.Kes selaku Dosen pembimbing lapangan dan juga kepada Bapak Dr Annis Catur Adi, Ir., M.Si selaku Dosen Pembimbing jurnal di Universitas Airlangga Surabaya, juga kepada suami, orangtua dan keluarga yang telah memberikan doa dan dukungan serta kepada teman-teman yang telah memberikan semangat dan motivasi untuk terselesainya penulisan jurnal penelitian ini. Semoga jurnal ini bermanfaat dan berguna bagi pembaca.

\section{REFERENSI}

1. Anwar, F. Keamanan Pangan. (Penebar Swadaya, 2004).

2. Rakyat, D. P. UU NO 18 Tahun 2012 Tentang Pangan. 18, 1689-1699 (2012).

3. Pavlov, A. dan P. C. Critical Control Points in Assesment of Microbiological risk in a small meat-processing enterprise. Bulg. J. Vet. Med. 7, 167-172 (2003).

4. Embarek, B. Safe Food Supply and Global Health-WHO's Perspective. in Proceeding 4th Asian Conference on Food Safety and Nutrition Safety, Bali, Indonesia (2004).

5. Pracoyo, N.E., S. Harjining, dan P. Penelitian Kuman-Kuman Patogen dalam Makanan Katering di Jakarta. Cermin Dunia Kedokt. 83, 1-4 (2008).

6. DPR-RI. Undang Undang No . 7 Tahun 1996 Tentang : Pangan. 4 (1996).

7. Menteri Kesehatan RI. Keputusan Menteri Kesehatan Republik Indonesia Tentang Persyaratan Hygiene Sanitasi Jasaboga. 1-56 12011). doi:10.1017/CBO9781107415324.004

8. Renosori, P., Ceha, R., Utami, R. Upaya Meningkatkan Pengendalian Kualitas Keamanan Pangan Ukm Melalui Penerapan Prinsip Hazard Analysis \& Critical Control Points (Haccp). in Prosiding Seminar Nasional Penelitian dan PKM: Sains, Teknologi dan Kesehatan 217-224 (2012).

9. Permenkes. Peraturan Menteri Kesehatan Republik Indonesia Nomor 1096/MENKES/PER/VI/2011 Tentang Higiene Sanitasi Jasaboga. Kementeri. Kesehat. 2008, (2011).

10. Departemen Kesehatan RI. Modul Khusus Hygiene Sanitasi Makanan dan Minuman. (2004). 